\title{
A RARE CASE OF UNICORNUATE UTERUS WITH PLACENTA PERCRETA CAUSING UTERINE RUPTURE IN SECOND TRIMESTER
}

\author{
Sudha R${ }^{1}$, Sunanda N², Lokeshchandra H. C 3 , Pranathi M ${ }^{4}$
}

\section{HOW TO CITE THIS ARTICLE:}

Sudha R, Sunanda N, Lokeshchandra H. C, Pranathi M. "A Rare Case of Unicornuate Uterus with Placenta Percreta Causing Uterine Rupture in Second Trimester". Journal of Evolution of Medical and Dental Sciences 2014; Vol. 3, Issue 28, July 14; Page: 7818-7821, DOI: 10.14260/jemds/2014/2978

ABSTRACT: Retained placenta postdelivery should raise suspicion of adherent placenta. In such cases immediate decision and quick action can be life saving. Placenta percreta can at times present in second trimester with ruptured uterus. Placenta percreta is an obstetric emergency often associated with massive hemorrhage leading to emergency hysterectomy. We describe a severe case of placenta percreta in which the placenta was left in situ, methotrexate administered and a delayed hysterectomy successfully performed. Delayed hysterectomy may be a reasonable management strategy in the most severe cases.

INTRODUCTION: A morbidly adherent placenta includes placenta accreta, increta or percreta. All together constitute approximately 1 in 2, 500 pregnancies. Placenta percreta is a rare, life threatening complication of pregnancy. ${ }^{1}$ In placenta percreta, the chorionic villi invade deeply up to the serosa and may even attach to surrounding organs such as urinary bladder and bowel. It constitutes about 5 $\%$ of all cases of adherent placenta. Maternal morbidity and mortality associated with Placenta accreta is mainly caused by massive obstetric hemorrhage or emergency hysterectomy, and placenta accreta is often diagnosed during delivery or immediately post-partum leading to an obstetric emergency.

Studies suggest that antenatal diagnosis may reduce obstetric hemorrhage-related morbidity. Furthermore, in some cases a morbidly adherent Placenta accreta can be left in situ. Such conservative management may allow delayed removal of the placenta to avoid massive hemorrhage during an attempted forced removal of the adherent placenta. We present a rare case of placenta percreta with uterine anomaly in second trimester of pregnancy treated conservatively initially followed with emergency laparotomy.

CASE REPORT: A young women para 1, living 1 abortion 1 presented to OPD with excessive bleeding per vaginum since $12 \mathrm{hrs}$. Patient had undergone emergency LSCS 2 yrs back in view of primi with breech. Second pregnancy was a spontaneous abortion of 5 months gestational age, 20 days back at home not followed with instrumental evacuation.

On examination pt had abdominal tenderness with minimal bleeding through os. On per vaginal examination patient had hot vagina, with a uterine size of 16-20 weeks with retained bits of products felt through os. After correcting anemia, instrumental evacuation was done and patient was sent for a check scan.

Following evacuation, USG - showed bulky uterus $13,2 \times 6.5 \times 9.8 \mathrm{cms}$ with mixed echogenic contents of $9.7 \times 3.8 \mathrm{cms}$ with increased vascularity seen in endometrial cavity. Diagnosis of placenta accreta was made and conservative treatment of 50mg methotrexate followed by inj.folinic acid 5gm 
i.m was given. Repeat scan showed involuting uterus with large hyperechoic retained product in body and fundus with thinning of posterior myometrium s/o placenta accreta.

Patient was taken up for emergency laparotomy. Per-op revealed aunicornuate uterus withRight rudimentary horn withincreased vascularity in left cornual region with a rent of $3 \mathrm{~cm}$ sealed by omentum. B/L tubes and ovaries present. Bladder and U.V fold adherent to LUS, hence proceeded with TAH.

Cut section revealed an adherent placenta with cord in the fundal area (non- scarred part of uterus), non communicating rudimentary horn without a cavity. A repeat $\beta$-hcg post- surgery was $93.40 \mathrm{mIU} / \mathrm{ml}$. She was transfused 2 pints packed cells in the post- operative period and put on broad spectrum antibiotics. Post op period was uneventful and she was discharged 10 days later.

Histopathology report showed chorionic villi invading the myometrium with absent decidual layer. Placental tissue shows chorionic villi with areas of calcification and haemorrhage.

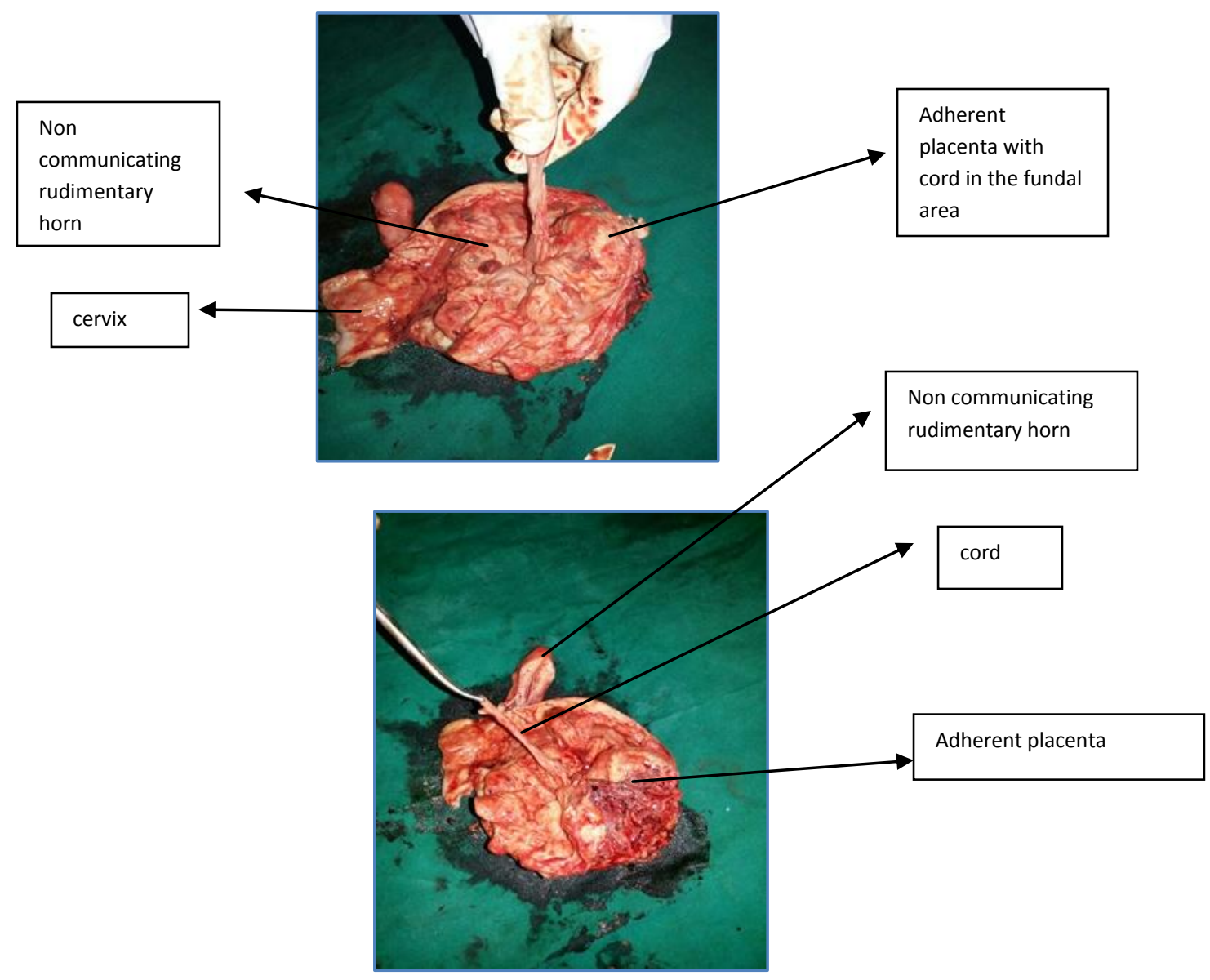

DISCUSSION: Morbidly adhered placenta is a serious obstetric complication of pregnancy that is associated with high maternal morbidity and mortality ${ }^{2}$. This is mainly caused by the massive hemorrhage when trying to deliver the placenta. Placenta percreta is considered to be the severe degree of the spectrum of abnormal placentation, where the placenta invades the full thickness of the uterine wall to reach the covering serosa. ${ }^{3} \mathrm{MAP}$ is thought to be due to an absence or deficiency of Nitabuch's layer or the spongiosus layer of the decidua. 
Several risk factors have been associated with this condition notably, placenta praevia, a previous caesarean section, multiple pregnancies, a history of dilatation and curettage, high parity and increasing maternal age. A previous scar is a major risk factor as the deciduas basalis in this zone is expected to be poorly vascularised and presents as a zone of weakness for subsequent placental villi penetration. ${ }^{4}$ The diagnosis of abnormal placentation is histological, and reveals the absence or poor development of the decidua basalis associated with varying extents of trophoblasatic villus invasion of the myometrium.

However, the sole use of histology to diagnose these conditions remains debatable. A high degree of clinical suspicion is paramount to better and quick diagnosis of the condition. ${ }^{5}$ However, it is usually seen in the third trimester.

The presentation here is rare since it occurred in the second trimester rendering clinical suspicion difficult as was evident in the case. Several diagnostic modalities may facilitate the antepartum diagnosis of abnormal placentation. These include transvaginal and trans- abdominal ultrasound with color imaging, and magnetic resonance imaging (MRI).

Non-specific biochemical markers have been associated with abnormal placentation such as maternal serum kinase and maternal alpha foeto- proteins which were not done in the absence of a presumptive diagnosis. The management of placenta percreta follows one of two options, radical surgery (hysterectomy) or conservative management with repair of the rent.

Traditionally, abdominal hysterectomy is the treatment of choice for placenta percreta and indicated in cases of severe hemorrhage as in our case. Though the conservative approach is believed to carry a higher risk of maternal death it preserves fertility and provides some psychological support to the woman.

It involves either of the following procedures: leaving the placenta in place with packing; a piecemeal blunt dissection with packing; uterine curettage with packing; closing of the uterine defect; localized excision and uterine repair; uterine packing with uterine or even hypogastric artery ligation; bilateral uterine artery embolization and pelvic artery ligation.

CONCLUSION: Placenta percreta is an obstetric emergency often associated with massive hemorrhage leading to emergency hysterectomy. We describe a severe case of placenta percreta in which the placenta was left in situ, methotrexate administered and a delayed hysterectomy successfully performed. Delayed hysterectomy may be a reasonable management strategy in the most severe cases.

\section{REFERENCES:}

1. Belfort MA: SMFM Publication Committee: placenta accreta. Am J ObstetGynecol 2010, 203:430439.

2. Sentilhes L, Ambroselli C, Kayem G, Provansal M, Fernandez H, Perrotin F, Winer N, Pierre F, Benachi A, Dreyfus M, Bauville E, Mahieu-Caputo D, Marpeau L, Descamps P, Goffinet F, Bretelle F: Maternal outcome after conservative treatment of placenta accreta. ObstetGynecol 2010, 115:526-534.

3. Sentilhes L, Kayem G, Ambroselli C, Provansal M, Fernandez H, Perrotin F, Winer N, Pierre F, Benachi A, Dreyfus M, Bauville E, Mahieu-Caputo D, Marpeau L, Descamps P, Bretelle F, Goffinet F: Fertility and pregnancy outcomes following conservative treatment for placenta accreta. 


\section{CASE REPORT}

Hum Reprod 2010, 25:2803-2810

4. Diop AN, Bros S, Chabrot P, et al., Placenta percreta: Urologic complication after successful conservative management by uterine arterial embolization: A case report, American Journal of Obstetrics and Gynaecology, 2009; 201: 7-8.

5. Hays A M, Worley KC, Roberts SR, Conservative management of placenta percreta: Experiences in two cases, Obstetrics and Gynaecology, 2008; 112: 425-426.

\section{AUTHORS:}

1. Sudha R.

2. Sunanda N.

3. Lokeshchandra H. C.

4. Pranathi M.

\section{PARTICULARS OF CONTRIBUTORS:}

1. Associate Professor, Department of Obstetrics and Gynaecology, Mysore Medical College and Research Center, Cheluvamba Hopsital.

2. Assistant Professor, Department of Obstetrics and Gynaecology, Mysore Medical College and Research Center, Cheluvamba Hopsital.

3. Professor and HOD, Department of Obstetrics and Gynaecology, Mysore Medical College and Research Center, Cheluvamba Hopsital.

4. Post Graduate, Department of Obstetrics and Gynaecology, Mysore Medical College and Research Center, Cheluvamba Hopsital.

\section{NAME ADDRESS EMAIL ID OF THE CORRESPONDING AUTHOR:}

Dr. Sudha R,

No. 12, 3rd Block,

$2^{\text {nd }}$ Stage, SBM Colony,

Srirampura, Mysore-570023,

Karnataka.

Email: drsudhaobgmmcri@gmail.com

Date of Submission: 26/06/2014.

Date of Peer Review: 27/06/2014.

Date of Acceptance: 07/07/2014.

Date of Publishing: 11/07/2014. 